\title{
Sorsby syndrome: a report on further generations of the original family
}

\author{
E M THOMPSON AND M BARAITSER \\ From the Clinical Genetics Unit, The Hospitals for Sick Children, Great Ormond Street, London WC1N $3 J H$.
}

SUMMARY Sorsby syndrome is a dominantly inherited combination of bilateral macular colobomas and apical dystrophy of the hands and feet (brachydactyly type B). We report on a further three affected members of the family originally described by Sorsby. Two of these have a single kidney, two have hearing loss, and one has a uterine anomaly.

In 1935 Sorsby $^{1}$ described a mother and five of her children who had bilateral macular colobomas and apical dystrophy of the hands and feet. We report on three affected members in two subsequent generations of this family, in order to enlarge the phenotype and re-examine in more detail the clinical features of this dominant condition.

Received for publication 30 August 1986.

Revised version accepted for publication 10 June 1987.

\section{Case reports}

CASE 1 (v.7, FIG 1)

The proband is a seven year old boy referred to the genetic clinic because of deafness. His maternal great grandmother, his maternal grandfather, and four sibs in that generation were the subjects of the original report of the Sorsby syndrome. ${ }^{1}$ The pregnancy was normal and labour

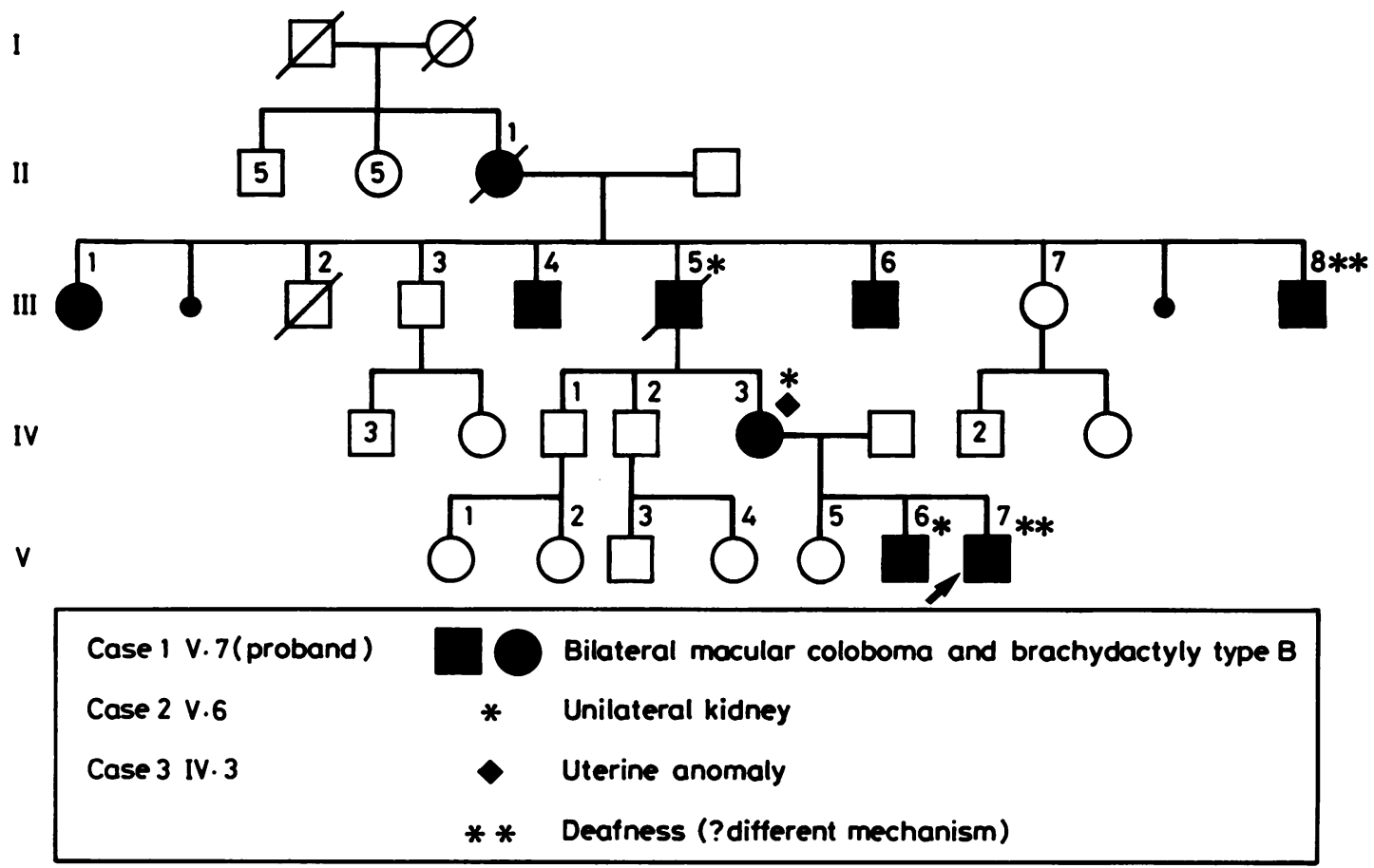

FIG 1 Pedigree of family. 
began spontaneously at 36 weeks' gestation. Delivery was by caesarian section, because the mother has a uterine anomaly (see case 3 ). Birth weight was $2555 \mathrm{~g}$.

\section{Hands and feet}

Symmetrical anomalies of the hands and feet were noted from birth. The hand defect (fig 2) comprised bifid thumbs with no nail on the medial element, aplasia of the nails of the index fingers, hypoplasia of the other finger nails, and short fifth fingers. There was partial skin syndactyly between the left middle and ring fingers. Radiographs (fig 3) showed duplication of the distal phalanx of both thumbs,

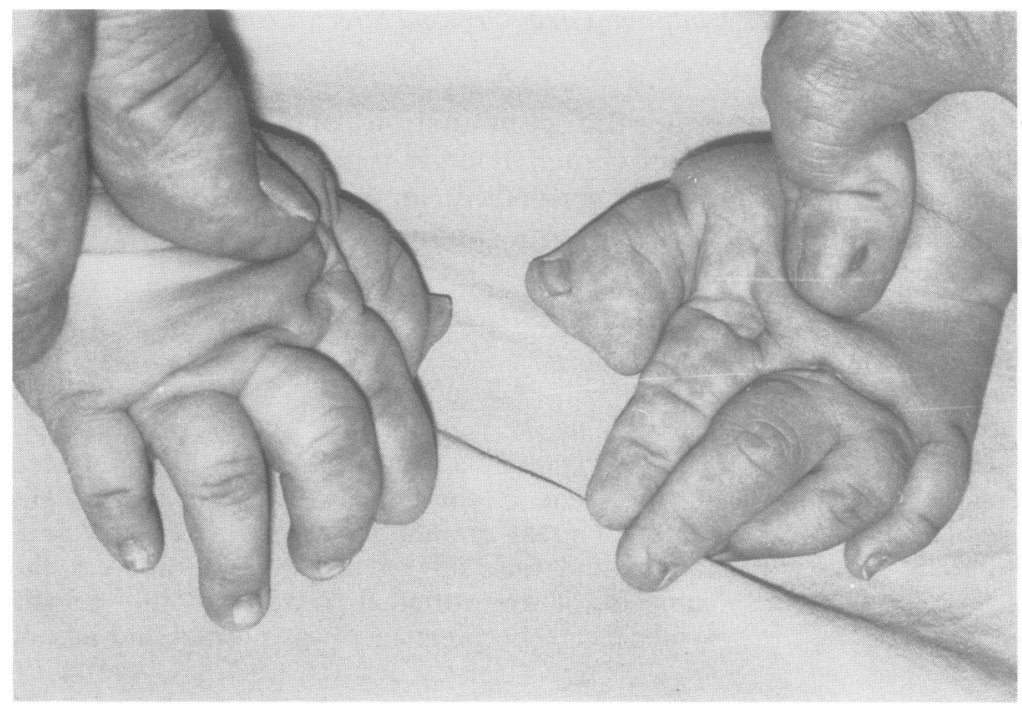

FIG 2 Hands of case 1. Note bifid thumbs, aplasia or hypoplasia of nails, and partial syndactyly between digits 3 and 4 on left.
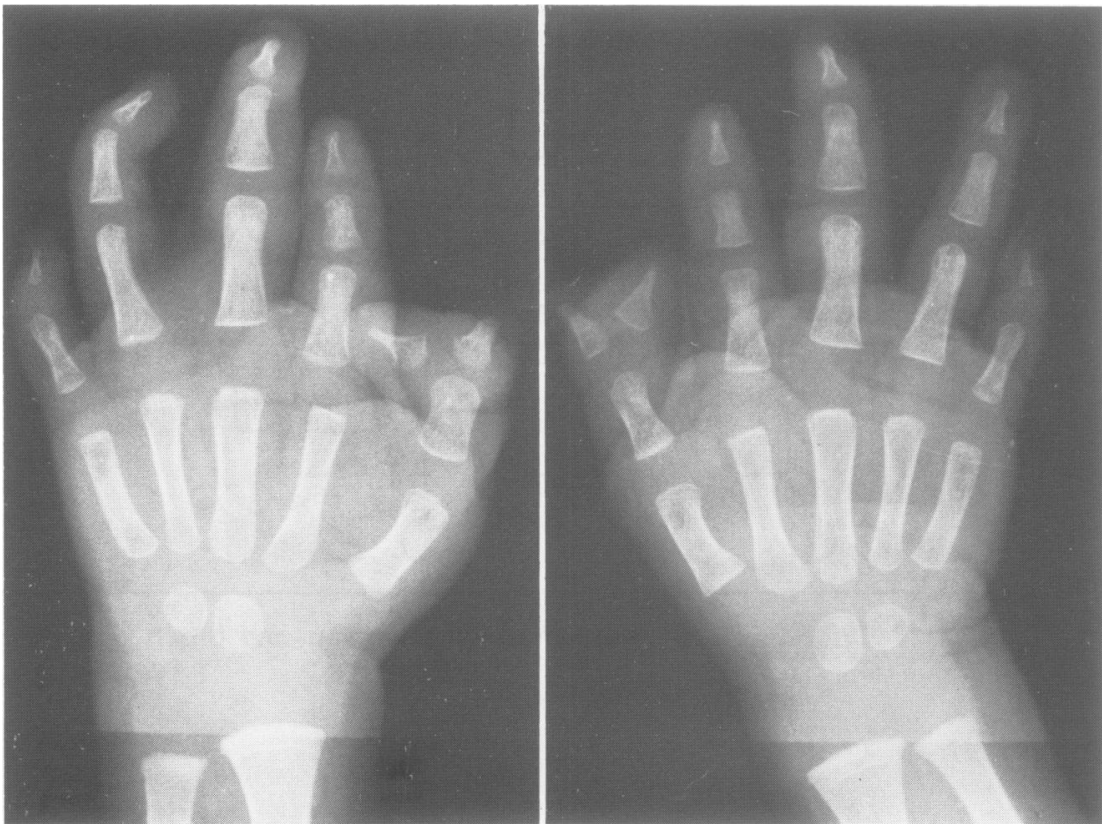

FIG 3 Radiographs of hands of case 1. Note duplication of distal phalanges of thumbs, hypoplastic distal phalanges, and only two phalanges in the fifth digits. 
hypoplastic distal phalanges of all fingers, and absent middle phalanges of the fifth fingers. In the feet (fig 4) the big toes appeared abnormally large and there was skin syndactyly between the fourth and fifth toes bilaterally. The toe nails were aplastic on the first and second toes and hypoplastic on the others. Radiographs (fig 5) showed that on the left, both of the phalanges of the big toe were duplicated.

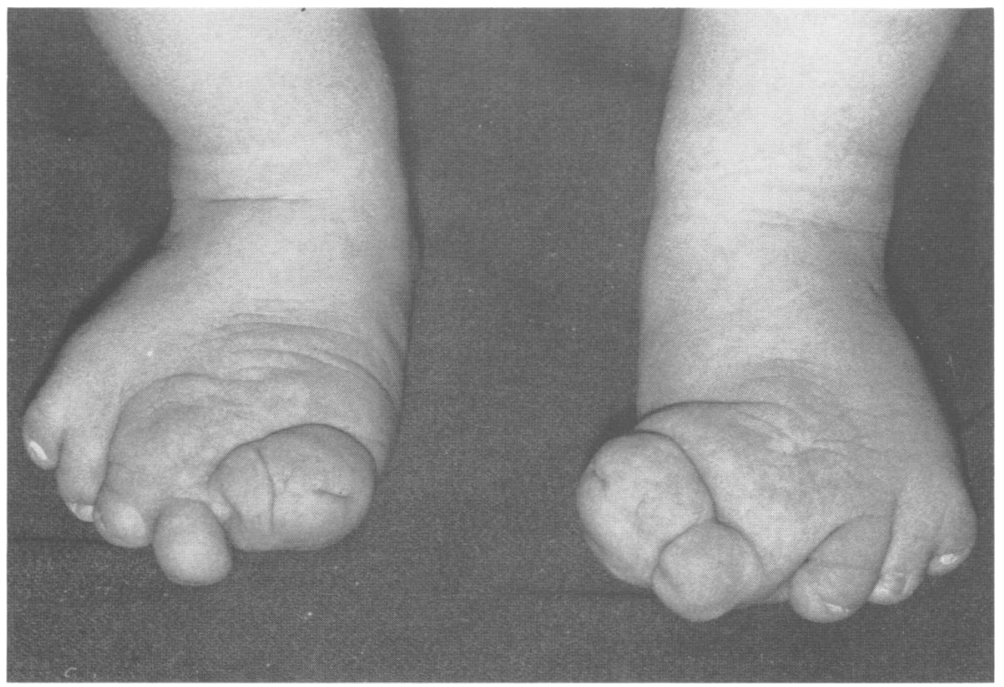

FIG 4 Feet of case 1. Note large halluces, abnormal nails, and syndactyly between fourth and fifth toes bilaterally.

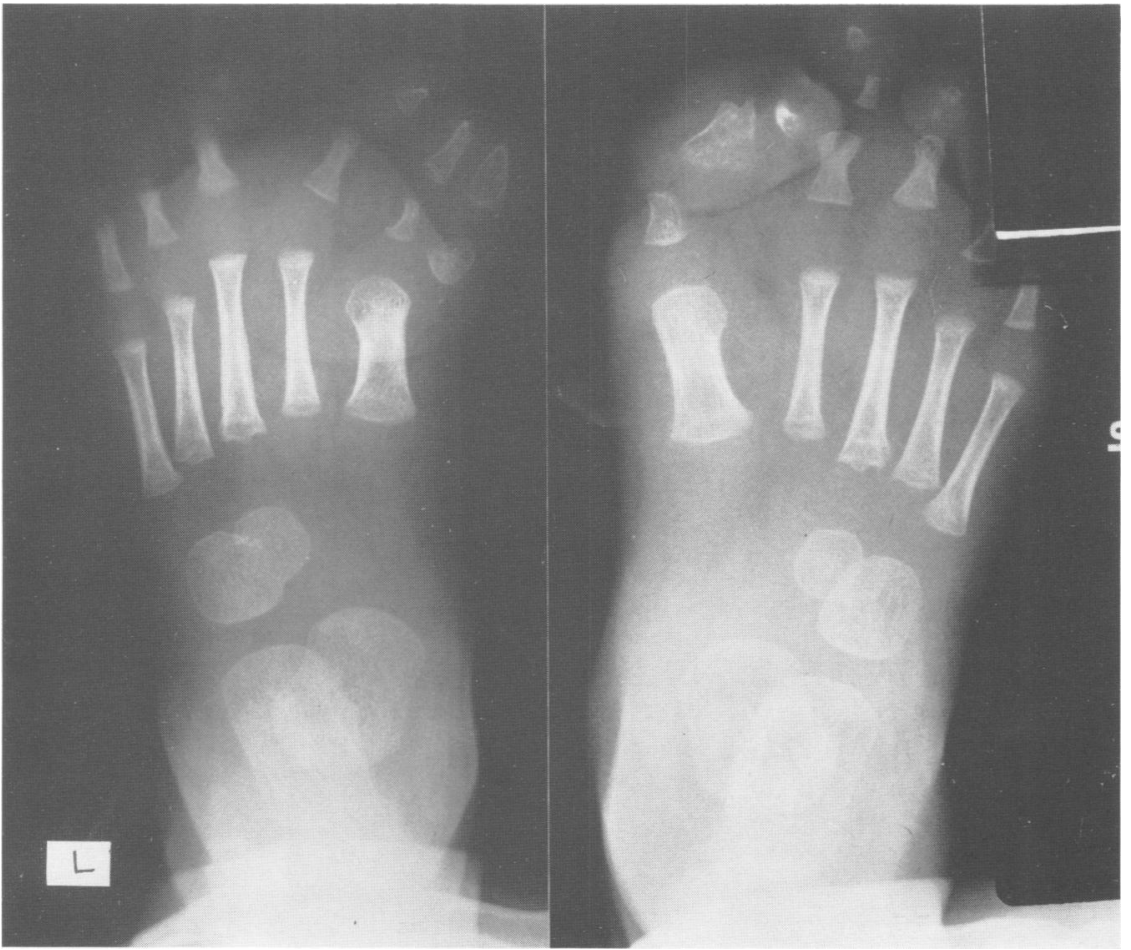

FIG 5 Radiographs of feet of case 1. Note duplication of both phalanges of left hallux, and of distal phalanx of right hallux. Other toes show varying degrees of hypoplasia or absence of distal and middle phalanges. 
The left second to fourth toes had proximal phalanges and pointed terminal phalanges only. The fifth toes had a proximal phalanx only. On the right, the terminal phalanx of the big toe was duplicated and its proximal phalanx was medially placed and of bizarre shape. The first and second metatarsals were shortened bilaterally. At 20 months the accessory thumbs were excised and at 29 months an operation was performed to straighten the big toes.

\section{Eyes}

Congenital pigmented colobomas of both maculae were found, associated with horizontal nystagmus. Visual acuity was poor (assessed as 4/24 with both eyes open at the age of six years).

\section{Hearing}

Hearing loss was detected at four years but had been suspected earlier. Audiograms recently indicated a severe bilateral sensorineural hearing loss of 70 to 80 $\mathrm{dB}$, worse at higher frequencies, with a probable superimposed permanent conductive low and midfrequency impairment, greater in the right ear. Hearing aids partially correct the deafness.

\section{Development}

The child was initially hypotonic and early milestones were delayed. He sat alone at one year. A recent assessment indicated normal non-verbal abilities.

Other skeletal anomalies

Marked plagiocephaly was present from birth but

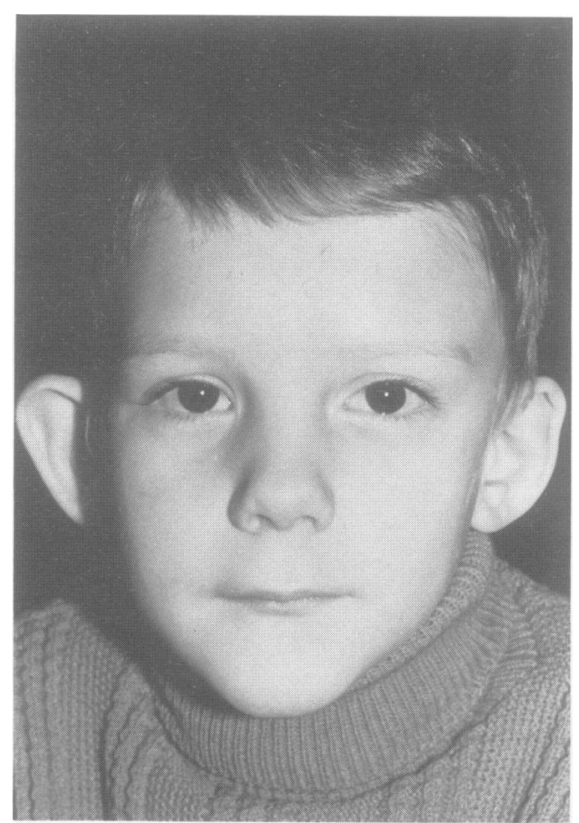

FIG 6 Case 1 at seven years. Note protuberant ears, more marked on the right side.

has improved. A mild thoracic scoliosis was noted at six months and has not worsened. There was a 13th rib on the right side.

Renal

An intravenous pyelogram was performed at 14

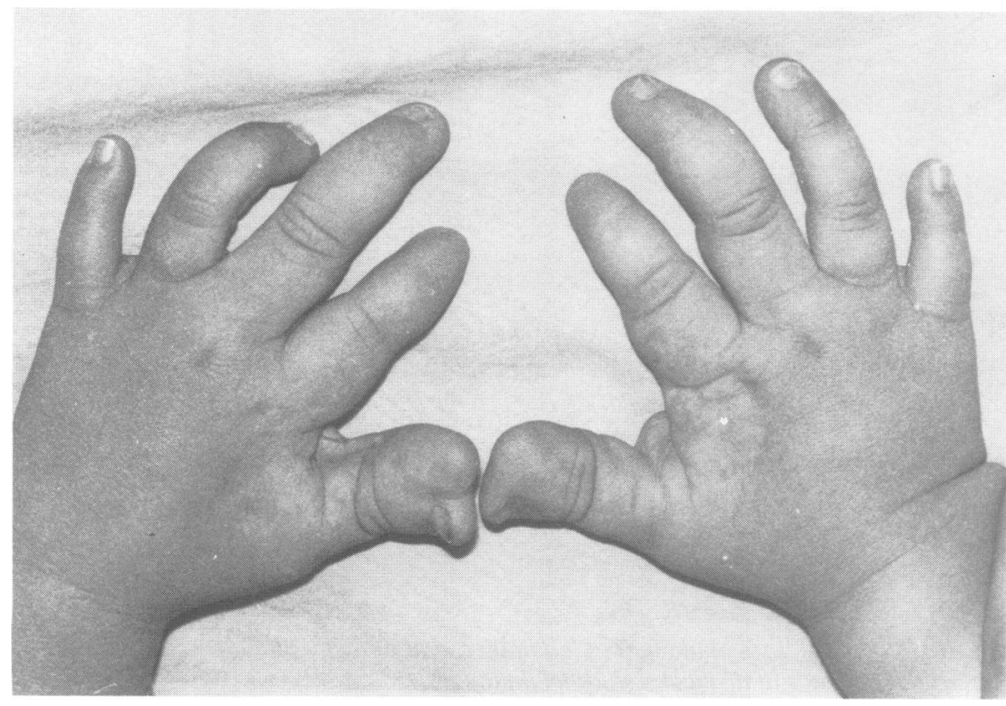

FIG 7 Hands of case 2. Note bifid thumbs and small or absent nails. 
months in view of renal anomalies in cases 2 and 3 and was normal.

When seen recently at seven years (fig 6) there was mild plagiocephaly, protuberant ears, and mild pendular nystagmus.

CASE 2 (v.6, FIG 1$)$

Case 2 is the older brother of case 1 and was recently seen at the genetic clinic aged eight years. He too was delivered by caesarian section because of the maternal uterine anomaly. Birth weight at term was $2760 \mathrm{~g}$.
Hands and feet

The hand anomalies were identical to those of case 1 , except that in case 2 the medial element of the left thumb had a middle and distal phalanx (figs 7 and 8 ). The feet were similar (figs 9 and 10) with hypoplasia or aplasia of the toe nails, syndactyly, missing or hypoplastic phalanges affecting predominantly the middle or distal phalanges (all phalanges were absent in the fifth toes), and duplication of the proximal and terminal phalanges between the right first and second toes. The proximal phalanges of the big toes were unusually large

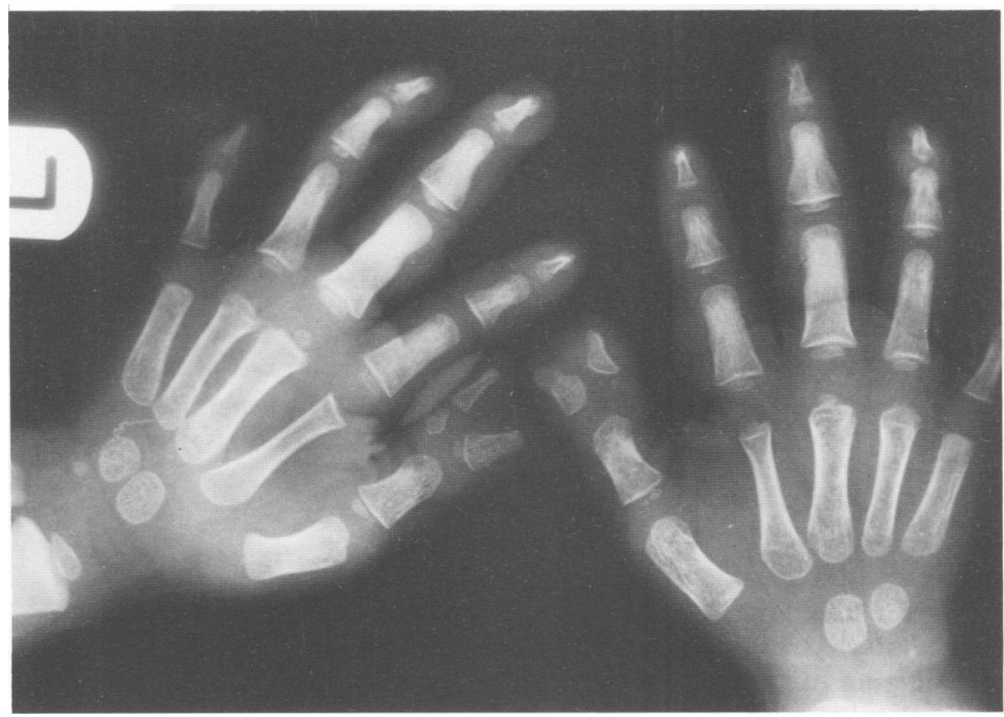

FIG 8 Radiographs of hands of case 2, similar to case 1 but medial element of duplicated left thumb has a middle phalanx.

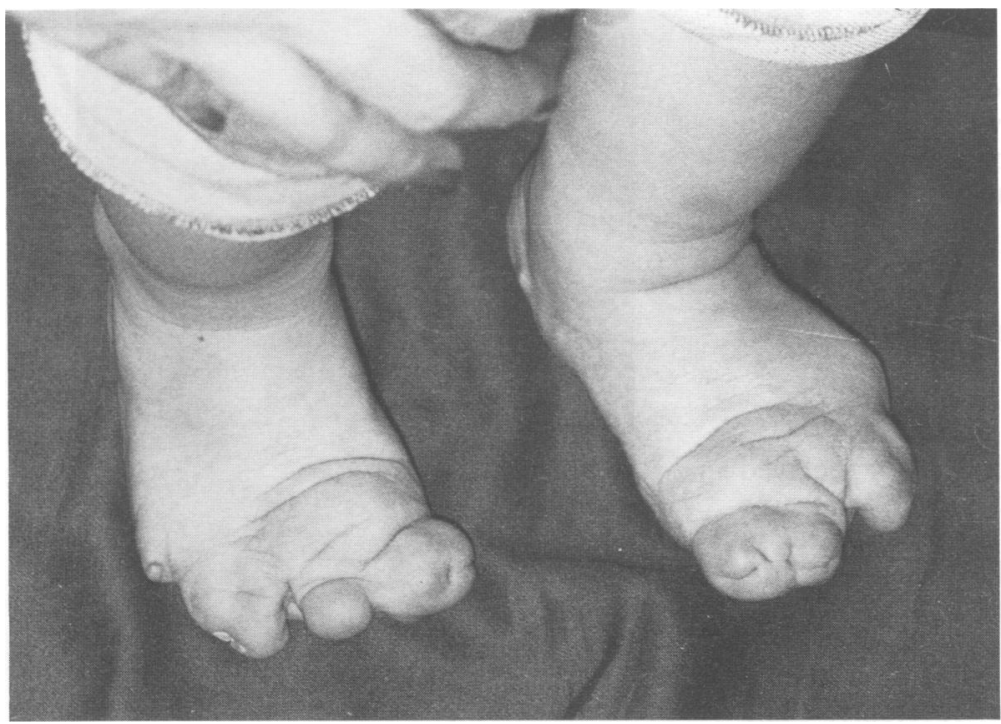

FIG 9 Feet of case 2. Note large halluces, small or absent nails, and syndactyly. 


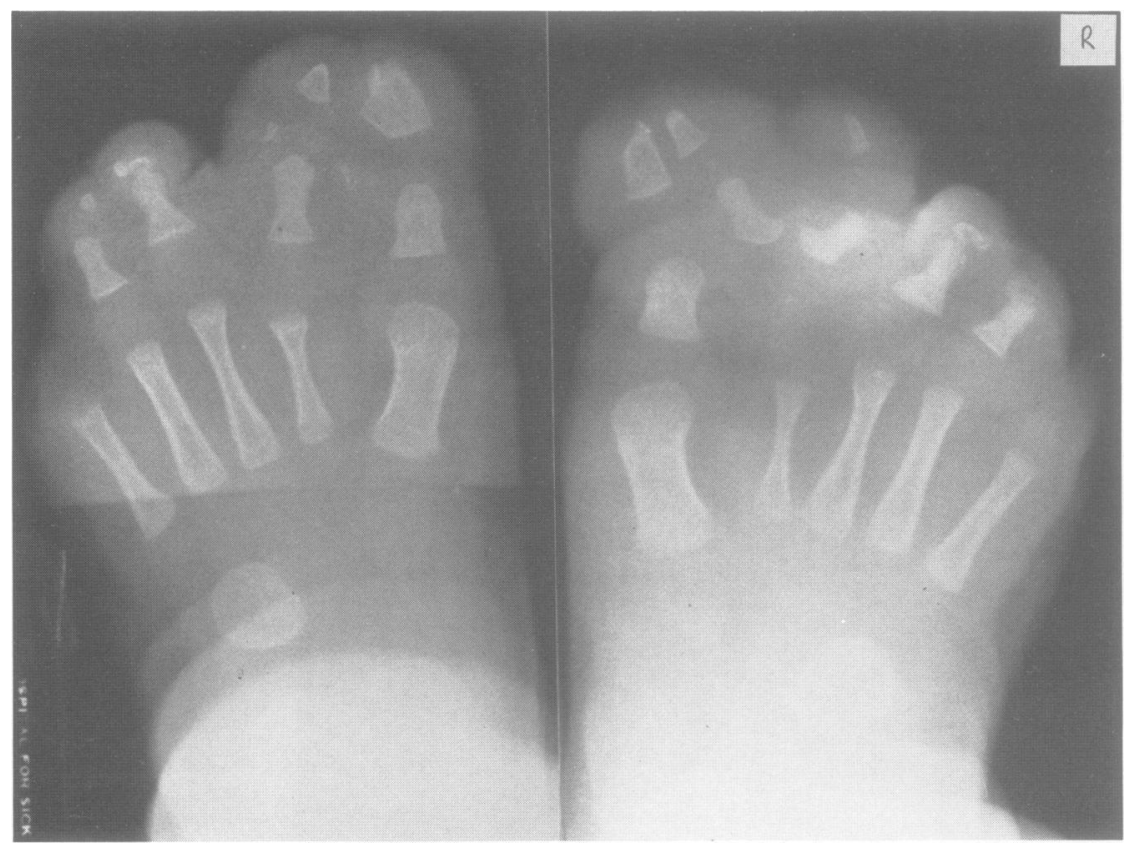

FIG 10 Radiographs of the feet of case 2. Note duplication of phalanges between first and second right toes and large distal phalanx of left hallux. Middle and distal phalanges of other toes are hypoplastic or absent and there is syndactyly.

and the first and second metatarsals were shortened bilaterally. The accessory thumbs were excised at three years of age and the fifth metatarsals were shortened at seven years to correct bulging of the overlying skin which had caused difficulty with footwear.

\section{Eyes}

Large bilateral pigmented colobomas of each macula associated with nystagmus were present from birth. Visual acuity at five years of age was $2 / 18$; this child also attends a school for the partially sighted.

\section{Renal}

Intravenous pyelogram at four months showed a normal functioning right kidney and ureter; no kidney was seen on the left.

\section{Development}

Hypotonia in infancy was followed by delayed milestones, for example, he first sat alone at nine months, walked at 18 months, and began to speak in single words at two years. At eight years intellectual abilities were in the normal range.

\section{Hearing}

Following tonsillectomy, adenoidectomy, and

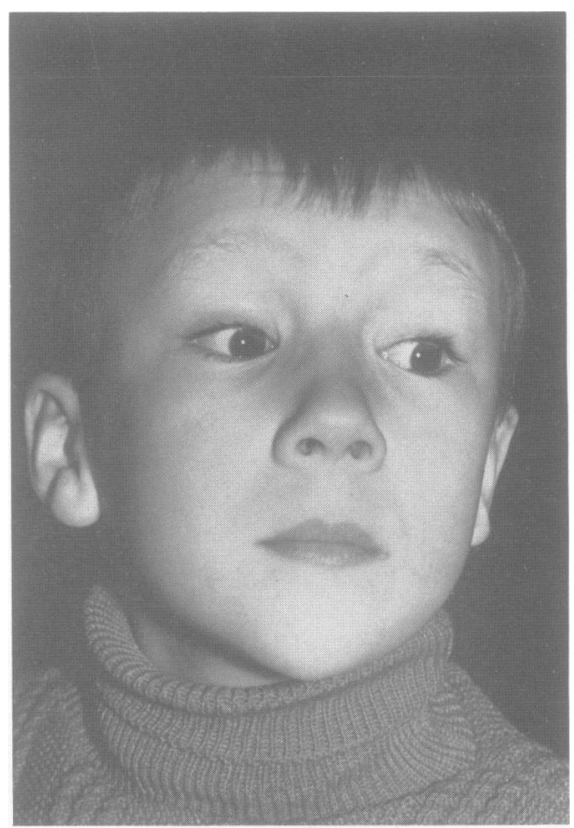

FIG 11 Case 2 at eight years. 
myringotomies at two years, hearing was normal and a recent audiogram was normal.

\section{Other skeletal anomalies}

There were 13 ribs bilaterally. The spine was normal.

When seen at eight years, the facial appearance was normal (fig 11). In addition to the anomalies

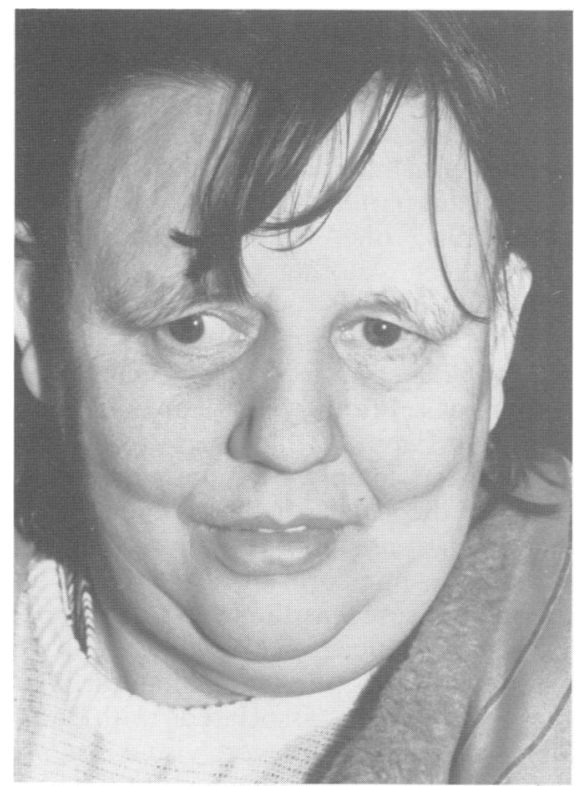

FIG 12 Case 3 (mother of cases 1 and 2). Note strabismus of right eye. described, joint laxity of most fingers was present except for stiffness of the interphalangeal joints of the fifth fingers.

CASE 3 (IV. 3 , FIG 1)

Case 3 (fig 12) is the mother of cases 1 and 2.

\section{Hands and feet}

The hand and foot anomalies were similar to those described above, with brachydactyly, nail defects, and syndactyly (fig 13). As in case 2, there was stiffness of the interphalangeal joint of the fifth fingers. In addition, the left index finger was deviated to the ulnar side at the distal interphalangeal (DIP) joint; there was camptodactyly at the DIP joints of the middle fingers.

\section{Eyes}

Bilateral pigmented macular colobomas were present (fig 14), associated with pendular nystagmus. She had attended a school for the partially sighted.

\section{Uterine and renal anomalies}

At 16 years of age, she presented with abdominal pain and a two year history of a yellow vaginal discharge. Cystoscopy showed that the right ureteric orifice was absent and at laparotomy the right kidney and ureter were absent. A cystic swelling was subsequently noted in the upper vagina on the left and under anaesthesia duplication of the vagina was found. The duplicated section contained purulent fluid and was drained. The diagnosis of uterus didelphys (double uterus) and double vagina was made. At 19 years laparotomy was performed for a

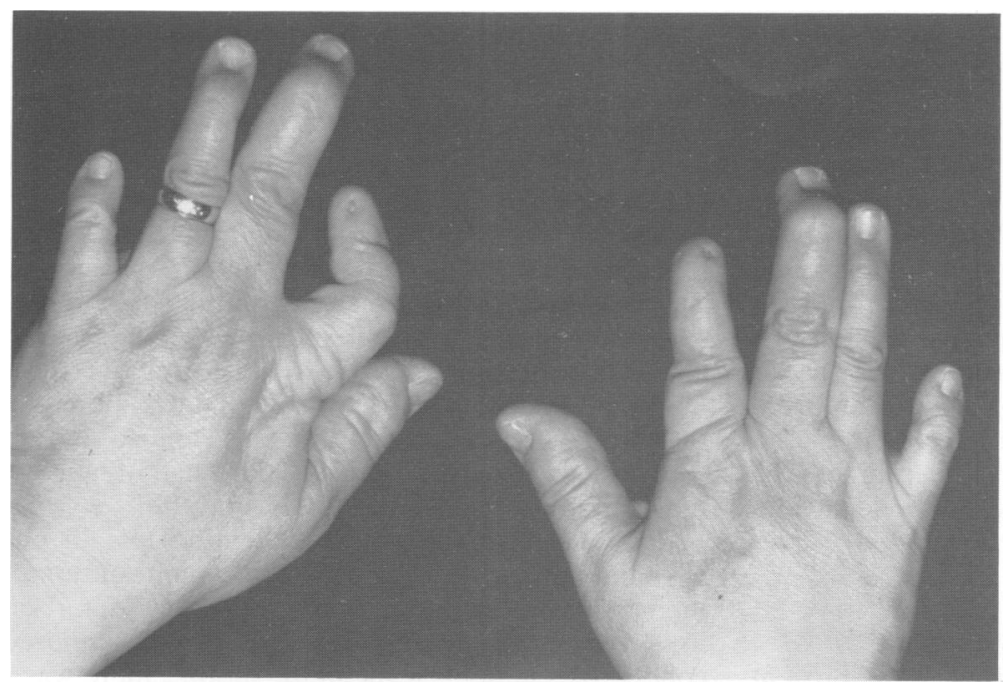

FIG 13 Hands of case 3, similar in appearance to those of her sons; note camptodactyly of DIP joints of third digits and deviation of PIP joints of second left digit. 


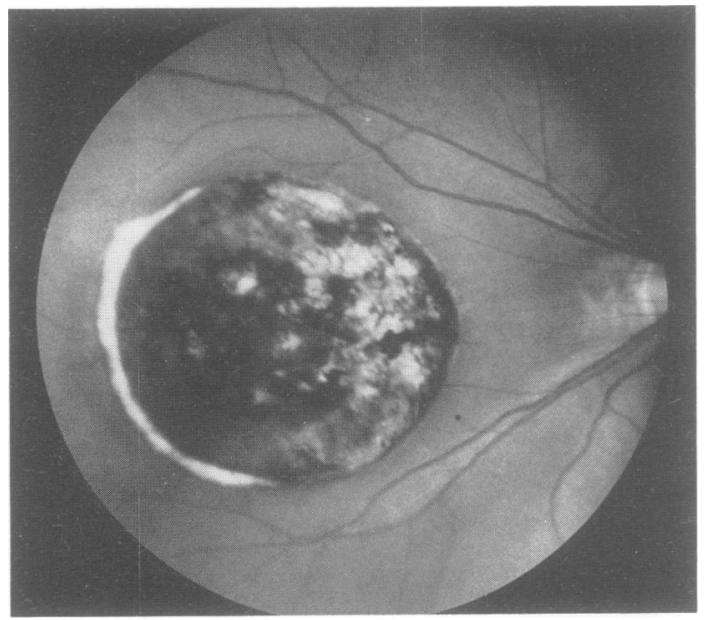

FIG 14 Right fundus of case 3. Note the pigmented retinal coloboma.

ruptured tubo-ovarian abscess, at which time the diagnosis of uterus didelphys was confirmed. The ovaries were normal. The right kidney was absent and the left kidney was lobulated, crescentic in shape, and hypertrophied.

\section{Hearing}

This was reported by the patient herself to be normal, but a recent audiogram revealed binaural mixed hearing impairment which was mild on the right ( $30 \mathrm{~dB}$ hearing loss) and moderate on the left side ( $55 \mathrm{~dB}$ hearing loss). Middle ear compliance was reduced in both ears.

Intellect was normal. Her hair was fine and thin, as was her affected grandmother's. A karyotype done recently was normal (46, XX, G banded).

The first child of case 3 is a 19 year old female (V.5, fig 1), born by caesarian section at term, birth weight $2890 \mathrm{~g}$. At five years, one kidney was removed because of hydronephrosis. At the age of 10 years unaided vision was $6 / 36$ bilaterally, but the eyes looked entirely normal with no colobomas. She was moderately myopic but her vision could be corrected to $6 / 6$ in each eye. Special schooling was required for mild intellectual handicap. The hands and feet were entirely normal. Hearing was reported to be normal by the patient but a recent audiogram revealed a mild binaural conductive hearing loss ( 35 $\mathrm{dB}$ loss on the right and $25 \mathrm{~dB}$ loss on the left). The karyotype was normal (46,XX, G banded).

\section{Discussion}

Since Sorsby described the ancestors of the present cases 50 years ago, no other identical cases have been reported. We did consider the following case reports, but believe all to be different. A brother and sister born to normal parents were described by Phillips and Griffiths. ${ }^{2}$ They had macular colobomas with defects of the hands and feet, but the latter are unlike those in Sorsby's cases. In addition, cleft palate was present in both and the female was mentally retarded. A child described by Smith $e t a l^{3}$ had severe, generalised, short limbed dwarfism with macular colobomas. Again, the acral defects differed from those in Sorsby syndrome. Bard ${ }^{4}$ described a family with congenital contractures and contractural arachnodactyly occurring in an autosomal dominant pattern. Two of the six affected had iris colobomas, one with a unilateral forearm reduction defect. Another relative had a unilateral optic disc coloboma, 'slender fingers', but no contractures. The acro-renal-ocular syndrome described by Halal et $a l^{5}$ in seven subjects from three generations of a French-Canadian family is similar to the present family. Differences are that the acral defect consisted mainly of thumb hypoplasia and only three of the seven affected subjects had ocular defects, which consisted of colobomas in only two. All seven had some form of urinary tract anomaly but in none of these was the defect a single kidney.

All affected subjects in the family described by Sorsby and in this report have bilateral pigmented macular colobomas, associated with horizontal pendular nystagmus and severe visual loss. Another constant feature is the involvement of the hands and feet which Sorsby called apical dystrophy and which is the same as brachydactyly type B (McKusick No 12040). ${ }^{67}$ Features are shortening of the middle and terminal phalanges of the second to fifth digits, absent or hypoplastic nails, broad or bifid thumbs and halluces, and syndactyly. The distal phalanges may be absent. Shortened metacarpals and metatarsals are not usually seen in brachydactyly type B, but occur in brachydactyly type E. However, the other features in our patients conform more closely to type B. In addition, in Sorsby syndrome there may be flexion deformities of the joints of some digits. The other skeletal defects of scoliosis, plagiocephaly, and 13 ribs noted in our patients were not apparently present in the original cases.

The finding of asymptomatic unilateral kidney in the mother and one son in this report and in 'Edward' in Sorsby's report (III.5, fig 1) suggests that this may be part of the syndrome.

It is not clear whether the hearing loss in our proband and his mother is another manifestation of the syndrome. In the proband the defect comprised a severe sensorineural loss with a superimposed conductive element, while in the mother there was a 
mild mixed hearing loss. 'James' reported by Sorsby (III.8, fig 1) was "very deaf" at 16 years, but this apparently dated from bilateral mastoidectomies at 13 years. Our proband's sister has a mild conductive hearing loss but does not have macula colobomas nor brachydactyly type B and on present evidence does not seem to have Sorsby syndrome.

Similarly the duplication of the uterus and vagina seen in the mother in this report may or may not be part of the syndrome. It is uncertain whether Sorsby syndrome can be added to the nine syndromes with acral and Müllerian anomalies recently summarised by Halal. ${ }^{8}$ Only one of these (Meckel syndrome) is associated with ocular colobomas. Several are associated with renal tract defects (hydrometrocolpos-polydactyly, cryptophthalmos, the syndromes of Rudiger et al and of Winter et al, Meckel syndrome, and acro-renal-mandibular syndrome) and some with ear anomalies.

The authors thank Dr Christine Sloczynska and Dr Gerald McEnery for referring the family for genetic counselling and $\mathrm{Mr}$ Brian Beverage, consultant ophthalmologist, who first drew attention to the correct diagnosis in the proband. We thank $\mathrm{Dr}$ Christine Hall for interpreting the $x$ rays and $\mathrm{Dr}$ Peter Watkins for providing the results of hearing tests. The Medical Illustration Departments of The Hospital for Sick Children, Great Ormond Street, and of the National Hospital for Nervous Diseases, Queen Square kindly provided the early photographs of cases 1 and 2 and the fundus photograph, respectively. We also thank Mrs Melanie Barham for secretarial assistance.

\section{References}

1 Sorsby A. Congenital coloboma of the macula, together with an account of the familial occurrence of bilateral macular coloboma in association with apical dystrophy of the hands and feet. $\mathrm{Br} J$ Ophthalmol 1935;19:65-90.

2 Phillips CI, Griffiths DL. Macular coloboma and skeletal abnormality. Br J Ophthalmol 1969;53:346-9.

${ }^{3}$ Smith RD, Fineman RM, Sillence DO, et al. Congenital macular colobomas and short-limbed skeletal dysplasia. Am J Med Genet 1980;5:365-71.

4 Bard LA. Congenital contractural arachnodactyly and intraocular colobomas. Birth Defects 1979;XV(5B):189-205.

5 Halal F, Homsy M, Perreault G. Acro-renal-ocular syndrome: autosomal dominant thumb hypoplasia, renal ectopia, and eye defect. Am J Med Genet 1984;17:753-62.

${ }^{6}$ McKusick VA. Mendelian inheritance in man. 7th ed. Baltimore, London: Johns Hopkins University Press, 1986.

${ }^{7}$ Fitch N. Classification and identification of inherited brachydactylies. J Med Genet 1979;16:36-44.

${ }^{8}$ Halal F. A new syndrome of severe upper limb hypoplasia and Müllerian duct anomalies. Am J Med Genet 1986;24:119-26.

Correspondence and requests for reprints to $\mathrm{Dr}$ E Thompson, Clinical Genetics Unit, The Hospitals for Sick Children, Great Ormond Street, London WC1N 3JH. 